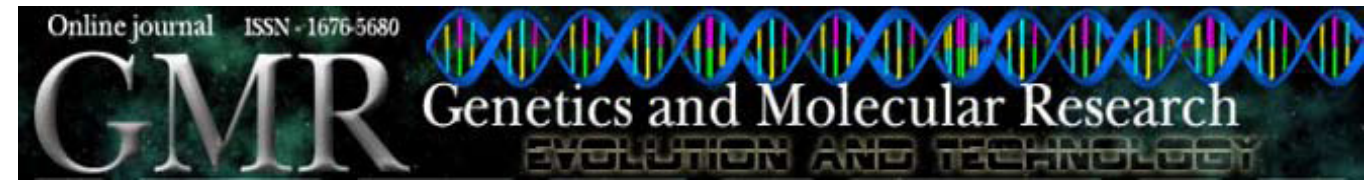

\title{
Somatic cell nuclear transfer is associated with altered expression of angiogenic factor systems in bovine placentomes at term
}

\author{
D.B. Campos ${ }^{1}$, P.C. Papa ${ }^{1}$, J.E.B. Marques Jr. ${ }^{1}$, F. Garbelotti ${ }^{1}$, \\ L.A. Fátima ${ }^{1}$, L.P. Artoni1 ${ }^{1,6}$, E.H. Birgel Jr. ${ }^{2}$, F.V. Meirelles ${ }^{3}$, \\ J. Buratini Jr. ${ }^{4}$, R. Leiser ${ }^{5}$ and C. Pfarrer ${ }^{6}$ \\ ${ }^{1}$ Departamento de Cirurgia, Setor de Anatomia, Faculdade de Medicina \\ Veterinária e Zootecnia, Universidade de São Paulo, São Paulo, SP, Brasil \\ ${ }^{2}$ Departamento de Clínica Médica, Faculdade de Medicina Veterinária e Zootecnia, \\ Universidade de São Paulo, São Paulo, SP, Brasil \\ ${ }^{3}$ Departamento de Ciências Básicas, \\ Faculdade de Zootecnia e Engenharia de Alimentos, \\ Universidade de São Paulo, São Paulo, SP, Brasil \\ ${ }^{4}$ Departamento de Fisiologia, Instituto de Ciências Biomédicas, \\ Universidade Estadual Paulista, Campus de Botucatu, Botucatu, SP, Brasil \\ ${ }^{5}$ Department of Veterinary Anatomy, Histology and Embryology, \\ Justus-Liebig University Giessen, Giessen, Germany \\ ${ }^{6}$ Department of Anatomy, University of Veterinary Medicine Hannover, \\ Hannover, Germany \\ Corresponding author: D.B. Campos \\ E-mail: camposdb@usp.br
}

Genet. Mol. Res. 9 (1): 309-323 (2010)

Received November 3, 2009

Accepted November 17, 2009

Published February 23, 2010

ABSTRACT. Low efficiency of somatic cell cloning by nuclear transfer has been associated with alterations of placental vascular architecture. Placental growth and function depend on the growth of blood vessels; VEGF-A and bFGF are the most important factors controlling neovascularization and vascular permeability in the placenta. We hypothesize that the VEGF-A and bFGF systems are disrupted in placentomes from cloned animals, contributing to the 
placental abnormalities that are common in these clones. We determined mRNA expression and protein tissue localization of VEGF-A, bFGF, and their receptors in placentomes from cloned and non-cloned bovine fetuses at term. Real-time RT-PCR revealed that VEGFR-2 mRNA was increased in cloned male-derived placentomes, while mRNA of bFGF and its receptors were decreased in placentomes of cloned females. VEGF-A system proteins were found to be located in placentomal endothelial, maternal and fetal epithelial and stromal cells; there was a variable pattern of cellular distribution of these proteins in both cloned and non-cloned animals. Alterations in the expression of VEGF-A and bFGF systems suggest that angiogenic factors are involved in abnormal placental development in cloned gestations, contributing to impaired fetal development and poor survival rates.

Key words: Vascular endothelial growth factor; Clones; Bovines; Fibroblast growth factor; Placenta

\section{INTRODUCTION}

Somatic cell cloning by nuclear transfer has been successfully performed in many mammalian species. However, cloning efficiency remains extremely low (Cezar et al., 2003; Campbell et al., 2005). Furthermore, live cloned offspring are not necessarily healthy (Cezar et al., 2003; Fulka Jr. and Fulka, 2007). The inefficiency of this technique is strongly related to placental abnormalities, which can cause both early and late fetal losses (Hill et al., 2000; Heyman et al., 2002) and post-natal mortality (Cezar et al., 2003; Loi et al., 2006). Placental vascular abnormalities have been described in cloned bovine (Hill et al., 2000) and ovine (De Sousa et al., 2001) fetuses, presumably due to abnormal aberrant gene expression (Humpherys et al., 2002; Inoue et al., 2002) and DNA methylation (Ohgane et al., 2001; Dindot et al., 2004).

The placenta is a key endocrine organ in pregnancy, controlling the maintenance of a suitable fetal environment (Malassine et al., 2003). Placental development and function are critical for pregnancy success and largely dependent on vessel formation in both fetal and maternal compartments (Reynolds and Redmer, 1995). Vascular formation in the placenta involves the coordinated processes of vasculogenesis and angiogenesis requiring the interaction of inhibitory and stimulatory growth factors (Reynolds and Redmer, 2001). Vascular endothelial growth factor (VEGF)-A and basic fibroblast growth factor (bFGF) are considered to be the major factors stimulating tissue neovascularization in the placenta (Reynolds and Redmer, 2001; Otrock et al., 2007).

Both factors belong to one of the major families of heparin-binding angiogenic molecules. VEGF-A is well known as a regulator of migration and proliferation of endothelial cells and vascular permeability. Moreover, VEGF-A plays alternative functions in non-endothelial cells, such as the induction of monocyte migration (Clauss et al., 1996) and axonal outgrowth of neurons and glial cells (Carmeliet and Storkebaum, 2002). The biological actions of VEGF-A are mediated by the activation of two specific tyrosine kinase receptors, VEGFR-1 (Flt-1/fms-like tyrosine kinase receptor 1) and VEGFR-2 (KDR/kinase insert domain-containing region), and further modulated by the recruitment of co-receptors, such as neurophilins 1 and 2, heparan sulfate, integrins, or cadherins (Cebe-Suarez et al., 2006). bFGF is unique among the major angiogenic growth factors in that it is pleiotropic and influences not 
only angiogenesis but has also various other functions in development and differentiation (Gospodarowicz, 1991). bFGF achieves its function by interacting with tyrosine kinase receptors (FGFR-1-4) (Klint and Claesson-Welsh, 1999) and heparan sulfate proteoglycans (Schlessinger et al., 1995).

The VEGF-A and bFGF systems have been identified in the placental tissue of several species, including the cow (Pfarrer et al., 2006a,b). In this species, VEGF-A, bFGF and its receptors were found throughout gestation not only in vascular endothelial cells but also in endometrial and trophoblast cells (Pfarrer et al., 2006a,b). The localization of VEGF-A and bFGF receptors in maternal and fetal epithelial cells suggests that these growth factors might regulate other functions than vascular development and permeability in the bovine placenta, including for example an autocrine action on binucleate trophoblast giant cells (TGC) migration (Pfarrer et al., 2006b). Hoffert-Goeres and collaborators (2007) demonstrated that expression of most angiogenic factors, including VEGF and VEGFR-1, are not altered as a result of nuclear transfer procedure in maternal and embryonic placental tissues at day 30 of gestation, indicating that described perturbations in angiogenesis may occur subsequently during early placental development and throughout gestation. Given the importance of VEGF-A and bFGF for placental neovascularization, their potential role in regulating other placental functions and the occurrence of alterations in the gene profile in cloned animals, we hypothesize that the VEGF-A and bFGF systems may be disrupted in placentomes from cloned bovine fetuses, contributing to the abnormalities of the vascular system.

\section{MATERIAL AND METHODS}

\section{Sample collection}

Bovine clones were produced by somatic cell nuclear transfer as described before (Yamazaki et al., 2005). Non-cloned bovines were obtained by natural mating, since the somatic cell nuclear transfer process, and not in vitro manipulation, is reported to induce most alterations in gene expression (Everts et al., 2008). Research was approved by Bioethics Committees of the Faculty of Veterinary Medicine and Animal Sciences, Faculty of Animal Sciences and Food Engineering, University of São Paulo as well as the Faculty of Veterinary Medicine, UNESP, Jaboticabal.

Placentomes from cloned $(\mathrm{N}=8)$ and non-cloned $(\mathrm{N}=4)$ bovine fetuses were collected after caesarean sections at term. Characteristics of the cloned bovine fetuses are shown in Table 1. Placentomal tissues were either fixed for immunohistochemical analysis or immediately frozen in liquid nitrogen and kept at $-80^{\circ} \mathrm{C}$ until RNA extraction.

\begin{tabular}{|c|c|c|c|c|}
\hline Clone & Sex & Birth weight (kg) & Length of gestation (days) & Outcome \\
\hline $\mathrm{C} 1$ & Female & 42 & 294 & Survived 30 days \\
\hline $\mathrm{C} 2$ & Female & 37 & 283 & Survived 15 days \\
\hline $\mathrm{C} 3$ & Female & 41 & 290 & Survived \\
\hline $\mathrm{C} 4$ & Female & 40 & 260 & Stillborn \\
\hline $\mathrm{C} 5$ & Male & 35 & 293 & Survived \\
\hline C6 & Male & 37 & 290 & Survived \\
\hline $\mathrm{C} 7$ & Male & 57 & 289 & Stillborn \\
\hline C8 & Male & 14 & 292 & Survived $7 \mathrm{~h}$ \\
\hline
\end{tabular}




\section{Extraction of RNA and reverse transcription}

Placental tissues (one placentome per animal) were homogenized and total RNA was purified using Trizol ${ }^{\mathbb{B}}$ Reagent (Invitrogen Brazil Ltda.) according to manufacturer recommendations. Total RNA was measured by spectrophotometry at $260 \mathrm{~nm}$, and $1 \mu \mathrm{g} / \mathrm{sample}$ total DNase-treated RNA was reverse transcribed with the Superscript III kit (Invitrogen, Carlsbad, USA) following manufacturer instructions.

\section{Real-time polymerase chain reaction}

Real-time polymerase chain reaction (PCR) analyses were performed using an ABI 7500 Sequence Detection System (PE Applied Biosystems, Foster City, USA). VEGF-A, VEGFR-1, VEGFR-2, bFGF, FGFR-1, FGFR-2, FGFR-3, and FGFR-4 primers and probes (Table 2) were designed using the Assays-by-Design service from Applied Biosystems. Primers and probe for GAPDH (Table 2), used as endogenous control gene, were designed using the Primer Express Software (PE Applied Biosystems) and evaluated for their efficiency using a standard curve. In 96-well plates 31.25 ng cDNA diluted in $5 \mu \mathrm{L}$ nuclease-free water was added to a mixture containing $12.5 \mu \mathrm{L}$ TaqMan ${ }^{\circledR}$ Universal PCR Master Mix buffer (2X, Applied Biosystems); $1.0 \mu \mathrm{L}$ forward, reverse $900 \mathrm{mM}$ primers and $250 \mathrm{mM}$ probe (Applied Biosystems) and $6.5 \mu \mathrm{L}$ water to a final volume of $25 \mu \mathrm{L}$. All wells were sealed with MicroAmp Optical Adhesive Covers (Applied Biosystems), following complete mixture of all reagents. The following cycling parameters were employed: 2 min at $50^{\circ} \mathrm{C}, 10 \mathrm{~min}$ at $95^{\circ} \mathrm{C}$ and 40 cycles of $15 \mathrm{~s}$ at $95^{\circ} \mathrm{C}$ (denaturation) and $1 \mathrm{~min}$ at $60^{\circ} \mathrm{C}$ (annealing and extension). PCRs for target genes were conducted in quadruplicates for each sample and the expression was determined with relative quantification by linear regression of fluorescence data. Ratios were calculated using the equation "relative expression $=\mathrm{N} 0($ target gene $) / \mathrm{NO}(\mathrm{GAPDH})$ " with $\mathrm{N} 0$ values calculated by the LinRegPCR 7.0 (Linear Regression PCR) program (Roussel et al., 2007). The log-linear part of the curve used for analysis contained from four to six points with the highest $\mathrm{R} 2$ value.

\begin{tabular}{|c|c|c|c|}
\hline Gene (Gene Bank \#) & Oligonucleotide primers & Probes & Amplicon length (bp) \\
\hline VEGF-A & $\triangleright$ GCCCACTGAGGAGTTCAACAT & & \\
\hline (NM_174216) & $\triangleleft$ CTGGCTTTGGTGAGGTTTGATC & FAM-CACCATGCAGATTATGMGBNFQ & 60 \\
\hline VEGFR-1 & \GCCTGAAATCTACCAGATCATGTTG & & \\
\hline (X94263) & \TTCCACAAGCTCCACGAATCTT & FAM-ACAAAGACCCAAAAGAAAGMGBNFQ & 58 \\
\hline VEGFR-2 & - ACTGCAGTGATGGCGTCTT & & \\
\hline (X94298) & ४CTTGTAGGCTCCAGTATCATTTCCA & FAM-CTGTAAGATGCTCACAATTTMGBNFQ & 64 \\
\hline bFGF & -CCGGTCAAGGAAATACTCCAGTTG & & \\
\hline (NM_174056) & ४GGTCCTGTTTTGGGTCCAAGTTTAT & FAM-TATGTGGCACTGAAACGAMGBNFQ & 78 \\
\hline FGFR-1 & $\triangleright$ GGATGGCACCGGAGGC & & \\
\hline (NM_001110207) & $\triangle$ CCAAGACCACACGTCACTCT & FAM-CTTGTTTGACCGGATCTACMGBNFQ & 62 \\
\hline FGFR-2 & - TCGGAATGTAACTTTTGAGGATGCT & & \\
\hline (BC151652) & ४TCAACCATGCAGAGTGAAAGGA & FAM-CTTGGCGGGTAATTCMGBNFQ & 86 \\
\hline FGFR-3 & - GTGTCCTGCGCCTACCA & & \\
\hline (NM_174318) & \CCTCAGTCACCAGCACGTT & FAM-CTGTGGATGCACTTCTGMGBNFQ & 100 \\
\hline FGFR-4 & \GGAATGTATCTGCTGAGGATGCA & & \\
\hline (AF170490) & \AGGAAAGGCCGATGGAGTTG & FAM-CCAGGCAGGTGTACTCMGBNFQ & 66 \\
\hline GAPDH & - AAGGCCATCACCATCTTCCA & & \\
\hline (AB098985) & $\triangle$ CCAGCATCACCGCCACTT & VIC-CGAGATCCTGCCAACATMGBNFQ & 62 \\
\hline
\end{tabular}

$\mathbf{D}$ forward; $\boldsymbol{4}=$ reverse 


\section{Immunohistochemistry}

Placentomal tissues were fixed in 4\% phosphate-buffered formalin solution for $24 \mathrm{~h}$ and then embedded in Paraplast ${ }^{\circledR}$ resin (Merck, Darmstadt, Germany). Sections $(5 \mu \mathrm{M})$ were deparaffinized in xylene and rehydrated in a series of graded alcohols. Retrieval of antigens was performed by microwave treatment for $15 \mathrm{~min}$ in sodium citrate buffer $(10 \mathrm{mM}, \mathrm{pH}$ 6.0). Slides were immersed in PBS (phosphate-buffered solution, $\mathrm{pH}$ 7.2) containing $1 \%$ hydrogen peroxide for $20 \mathrm{~min}$ to quench endogenous peroxidase activity. Blocking of non-specific binding was performed using $10 \%$ horse serum in PBS for $30 \mathrm{~min}$, and sections were incubated for $20 \mathrm{~h}$ at $4{ }^{\circ} \mathrm{C}$ with primary antibodies (Table 3). After washes in PBS, sections were incubated with biotinylated horse anti-mouse/anti-rabbit second antibody for $1 \mathrm{~h}$. Following PBS washes, a complex of avidin-biotin-peroxidase (ABC-Method; Vectastain-Universal-ELITE-ABC-Kit ${ }^{\mathbb{B}}$, Vector Laboratories, Burlington, Ontario, Canada) was applied for $45 \mathrm{~min}$. After undergoing another rinsing procedure, the reaction was revealed by incubation with Vector NovaRed ${ }^{\circledR}$ for 5 min. Finally, sections were counterstained with hematoxylin and slides were mounted with glycerin (Merck, Darmstadt, Germany). Negative controls were set up with blocking peptides against VEGF-A, VEGFR-1 and VEGFR-2 (Blocking peptide sc-152 P, sc-316 P and sc-315 P; Santa Cruz Biotechnology, Heidelberg, Germany) as well as substituting the primary antibody through mouse (bFGF, FGFR-1) or rabbit (FGFR-2 and FGFR-3) antiserum (Guerra et al., 2008).

\begin{tabular}{|c|c|c|c|c|}
\hline Antibody & Clone, isotype & Host & Peptide sequence & Supplier (order number) \\
\hline Anti-VEGF-A & A-20, polyclonal & Rabbit & N-terminus of human VEGF-A & Santa Cruz (sc-152) \\
\hline Anti-VEGFR-1 & C-17, polyclonal & Rabbit & C-terminus of human VEGFR-1 & Santa Cruz (sc-316) \\
\hline Anti-VEGFR-2 & C-20, polyclonal & Rabbit & C-terminus of mouse VEGFR-2 & Santa Cruz (sc-315) \\
\hline $\mathrm{bFGF}$ & bFM-2, IgG $_{1 \mathrm{k}}$ monoclonal & Mouse & Purified bovine $\mathrm{bFGF}$ & Upstate (05-118) \\
\hline FGFR-1 & 19B2, $\mathrm{IgG}_{1}$ monoclonal & Mouse & Amino acids 23-325 of human FGFR-1 & Upstate (05-149) \\
\hline FGFR-2 & polyclonal & Rabbit & Amino acids $809-821$ of human FGFR-2 & Sigma (F 0300) \\
\hline FGFR-3 & polyclonal & Rabbit & Amino acids $792-806$ of human FGFR-3 & Sigma (F 0425) \\
\hline
\end{tabular}

\section{Statistical analysis}

Levels of mRNA are reported as means \pm SEM of triplicates for each animal studied. Means of relative mRNA expression were analyzed using a nonparametric two-tailed $t$-test. When variances were significantly different, the nonparametric two-tailed $t$-test with Welch's correction was applied. Means of non-cloned and cloned female and male bovine fetuses were analyzed by one-way ANOVA or the Tukey test. Probability level of $\mathrm{P}<0.05$ was considered to be significant. Statistical analyses were performed using the GraphPad Prism software (version 4.00 for Windows, GraphPad Software, San Diego, CA, USA).

\section{RESULTS}

\section{Levels of mRNA for VEGF-A, bFGF and their receptors in the placentome from cloned and non-cloned bovine fetuses}

Transcripts of VEGF system genes were detected in the placentae from all animals 
examined at 270 days of gestation. VEGF-A mRNA levels were not statistically different (P > $0.05)$ comparing placentomes from cloned and non-cloned male bovine fetuses. On the other hand, a tendency $(\mathrm{P}=0.09)$ of higher levels of VEGF-A mRNA was noticed in cloned female bovine fetuses compared with non-cloned animals. VEGFR-1 mRNA content did not differ among placentomes from male and female fetuses compared with non-cloned animals. In contrast, VEGFR-2 mRNA levels were higher in cloned male bovine fetuses than in non-cloned animals or in cloned female bovine fetuses $(\mathrm{P}<0.05)$ (Figure 1).

\section{A}

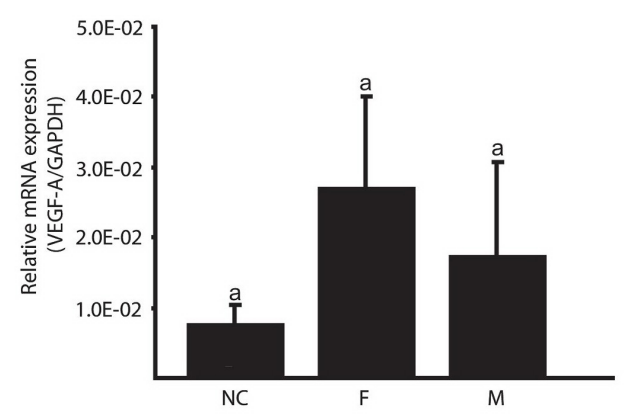

$\mathbf{B}$

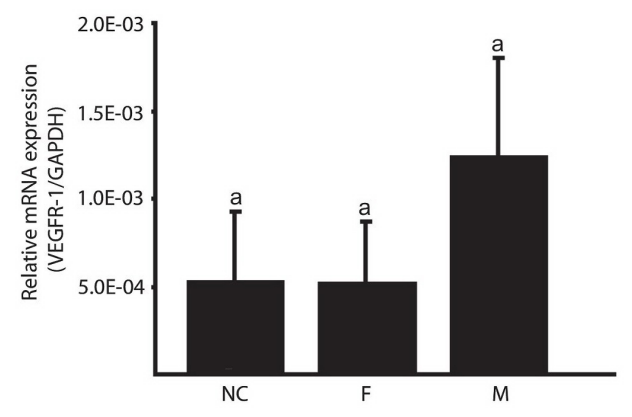

C

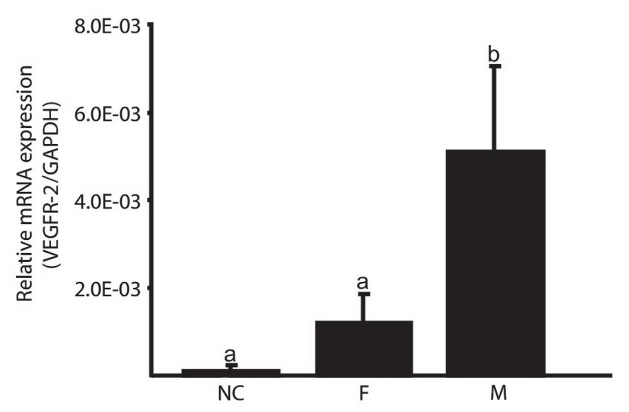

Figure 1. Relative mRNA expression of VEGF-A, VEGFR-1 and VEGFR-2 in placentomes from cloned and noncloned bovine fetuses. A. Real-time PCR analysis demonstrated no differences $(\mathrm{P}>0.05)$ in mRNA abundance of VEGF-A. A tendency of higher VEGF-A mRNA expression was observed in cloned female bovine fetuses $(\mathrm{P}=0.09)$. B. No differences were observed in VEGR-1 content among animals studied. C. VEGFR-2 gene expression was statistically significantly higher $(\mathrm{P}<0.05)$ in cloned male animals. $\mathrm{NC}=$ non-cloned bovine fetuses; $\mathrm{F}=$ cloned female bovine fetuses; $\mathrm{M}=$ cloned male bovine fetuses. $\mathrm{NC}, \mathrm{F}$ and $\mathrm{M}$ data represent means $\pm \mathrm{SEM}$ of 4 different animals. 
By analyzing the standard deviation of gene expression in the placentomes from cloned and non-cloned bovine fetuses, we observed that individual levels of VEGF-A system mRNA were more variable among the cloned bovine fetuses (Figure 2; $\mathrm{P}<0.05$ ).
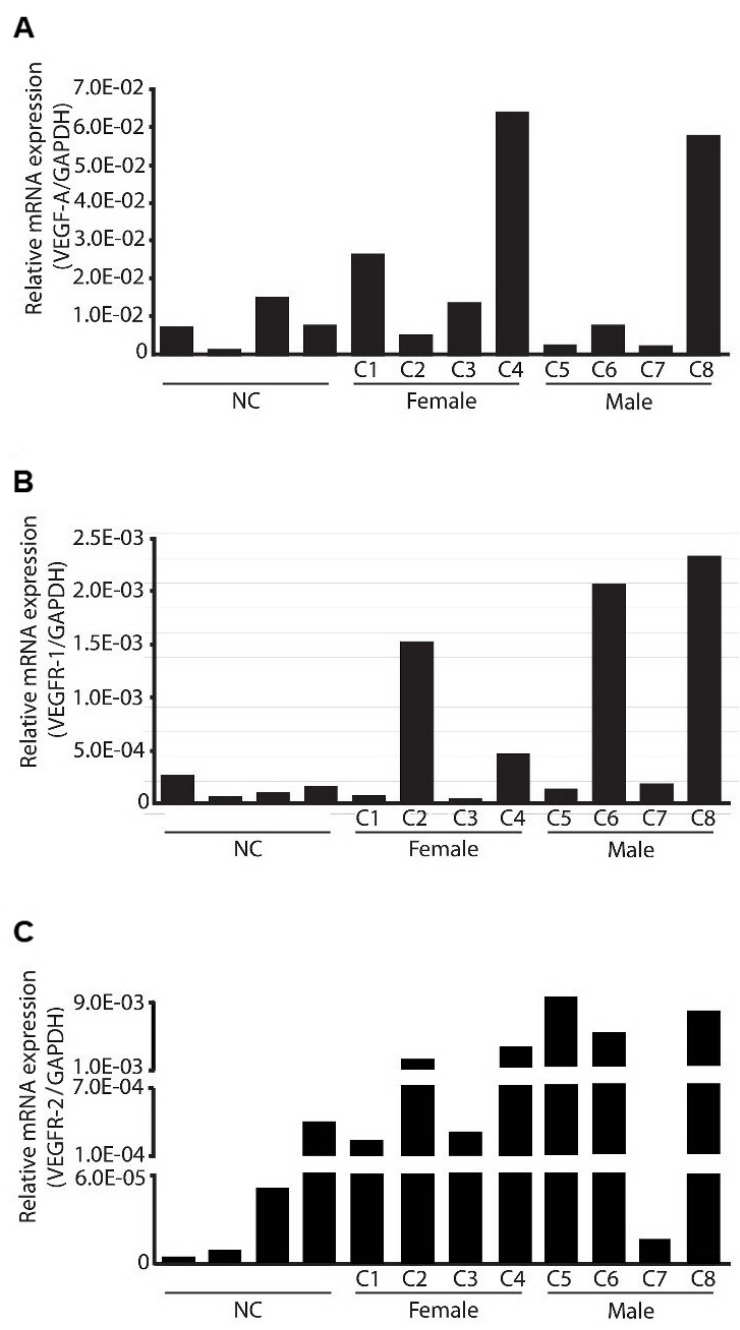

Figure 2. Relative mRNA expression of VEGF-A, VEGFR-1 and VEGFR-2 in placentomes from cloned and non-cloned bovine fetuses. Individual analysis showed that variations in the relative mRNA transcript abundance of VEGF-A (A), VEGFR-1 (B) and VEGFR-2 (C) occurred more frequently and with a higher variability in placentomes from cloned bovine fetuses $(\mathrm{C} 1-\mathrm{C} 8)$ than in placentomes from non-cloned $(\mathrm{NC})$ animals.

bFGF and receptor transcripts were also detected in all placentae from cloned and non-cloned fetuses. Interestingly, placentomes of cloned female fetuses showed a decrease $(\mathrm{P}<0.05)$ of all bFGF system genes examined either in comparison to both cloned male and 
control fetus placentomes. Cloned male and control placentomes showed no difference in relation to bFGF and receptor expression (Figure 3). Variances of cloned and non-cloned bovine fetuses bFGF system mRNA levels were not statistically different $(\mathrm{P}>0.05)$ (data not shown).

\section{A}

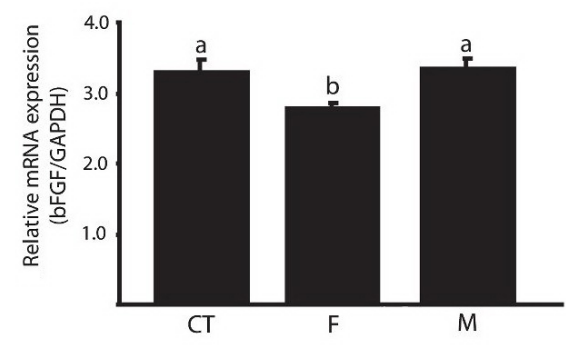

B

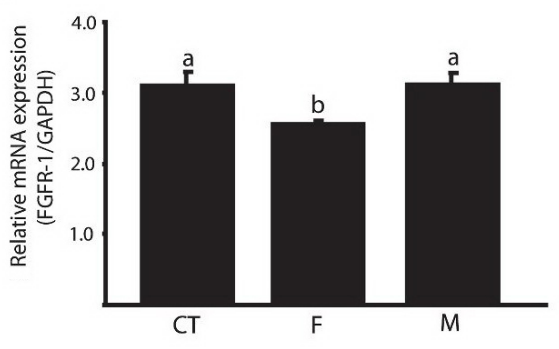

D

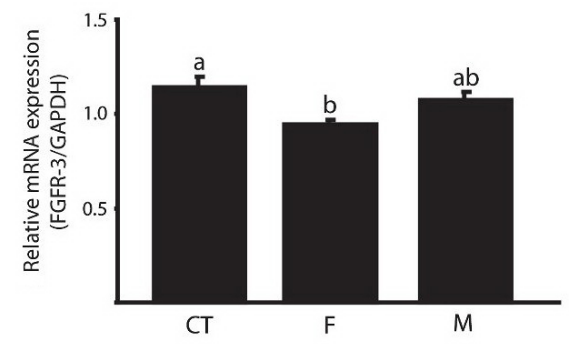

C

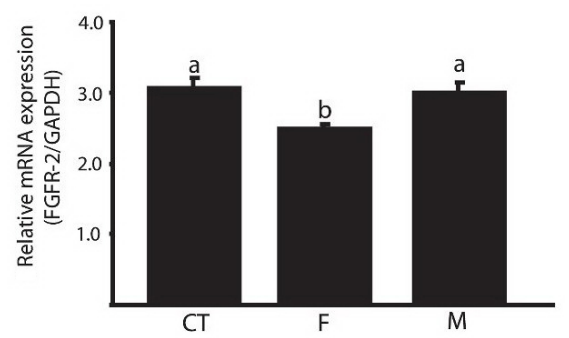

E

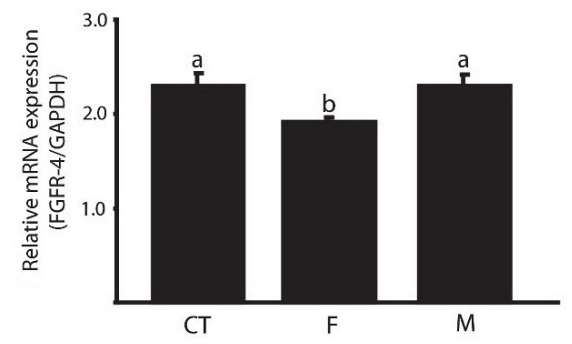

Figure 3. Relative mRNA expression of bFGF, FGFR-1, FGFR-2, FGFR-3, and FGFR-4 in placentomes from cloned and non-cloned bovine fetuses. Real-time PCR analysis demonstrated that placentomes from female cloned fetuses showed less bFGF system expression $(\mathrm{P}<0.05)$ than non-cloned animals $(\mathrm{A}-\mathrm{E})$ and male fetuses $(\mathrm{A}, \mathrm{B}, \mathrm{C}$, and $\mathrm{E}$ ). $\mathrm{NC}=$ non-cloned bovine fetuses; $\mathrm{F}=$ cloned female bovine fetuses; $\mathrm{M}=$ cloned male bovine fetuses. $\mathrm{NC}$, $\mathrm{F}$ and $\mathrm{M}$ data represent means \pm SEM of 4 different animals.

\section{Immunolocalization of VEGF-A, bFGF and their receptors in placentomes from cloned and non-cloned bovine fetuses}

VEGF-A, bFGF and their receptor proteins were spatially localized in placentomes from cloned bovine fetuses by immunohistochemistry. We observed these proteins in the dif- 
ferent placental cell types and identified considerable variations in cellular distribution between placentomes from cloned and non-cloned animals.

VEGF-A protein was localized in both maternal and fetal epithelial cells as well as stromal cells in placentomes from cloned and non-cloned bovine fetuses (Figure 4). Additionally, positive staining for VEGF-A was observed in endothelial cells from placentomal vessels. A similar VEGFA distribution was observed in 4 of the 6 clones studied (C2, C3, C5, and C7). In these animals, binucleate TGC, mononucleate trophoblast cells and maternal epithelial cells showed immunostaining for the protein (Figure $4 \mathrm{~b}$ ). Clone $\mathrm{C} 4$ showed a distinct pattern of expression, as some binucleate TGC and maternal epithelial cells presented both cytoplasmic and nuclear staining for the protein (Figure 4c). On the other hand, in the clone C1, VEGF-A was not expressed in binucleate TGC as observed in the other clones, a pattern similar to that observed in non-cloned animals (Figure $4 \mathrm{a}$ and d). Maternal stromal cells were positively labeled for the protein in the clones $\mathrm{C} 2$ and $\mathrm{C} 4$ (Figure $4 \mathrm{~b}$ and c). Compared with the VEGF-A expression in placentomal tissues from non-cloned bovine fetuses (Figures 4d), a stronger staining was observed in all clones studied.

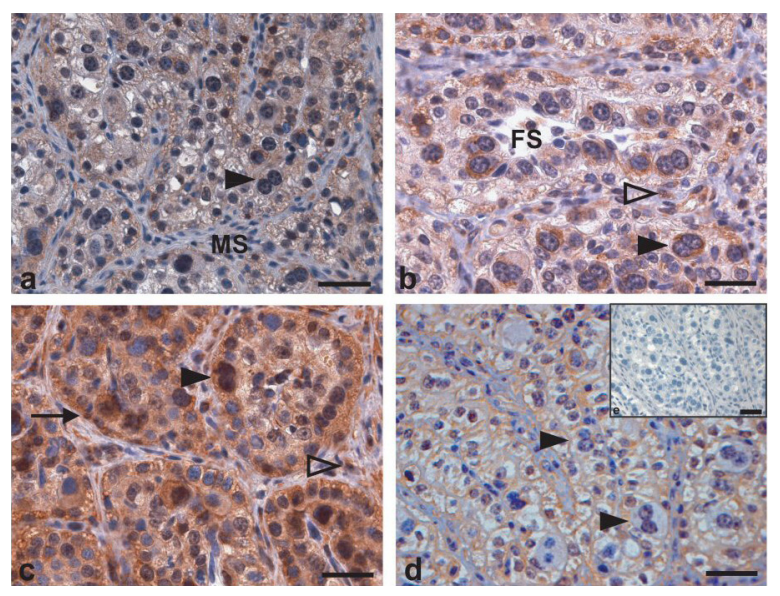

Figure 4. Immunolocalization of VEGF-A in placentomes from cloned and non-cloned bovine fetuses. a, b, c: Clones C1, C2 and C4, respectively. d: Non-cloned animal. e: Negative control. VEGF-A is expressed in fetal binucleate trophoblast giant cells (arrowhead) in the clones $\mathrm{C} 2$ and $\mathrm{C} 4$ (b and c). The maternal epithelium (arrow) shows the signal for VEGF-A in the clone C4 (c). VEGF-A is weakly expressed in binucleate trophoblast giant cells (arrowhead) from clone $\mathrm{C} 1$ (a) and non-cloned animals (d). Open arrowhead indicates positively stained maternal stromal cells. $\mathrm{MS}=$ maternal stroma; FS $=$ fetal stroma. Bars: $100 \mu \mathrm{M}$.

We further analyzed the localization of VEGF-A receptors in the placenta from cloned bovine fetuses. As observed for VEGF-A, receptors VEGFR-1 and VEGFR-2 were present in the maternal and fetal epithelium as well as in stromal and endothelial cells (Figure 5). The immunoreaction for VEGFR-1 was predominantly found in the maternal epithelium from clones $\mathrm{C} 3, \mathrm{C} 4$ and $\mathrm{C} 5$ (Figure 5b and c). This was a very similar pattern of expression of VEGFR-1 compared to placentomes from non-cloned fetuses (Figure 5d), although less strong in noncloned animals. On the other hand, this pattern was not observed in the placentomes from clone $\mathrm{C} 1$ (Figure 5a). In the clones $\mathrm{C} 2$ and $\mathrm{C} 7$, specific staining for the VEGFR-1 was predominantly found in binucleate TGC, while the labeling was not as prominent in the other cell types.

In analyzing VEGFR-2 spatial expression, we also observed that the localization of this 
receptor was variable between placentae from cloned and non-cloned animals and further varied among the individual clones. Strikingly, clone $\mathrm{C} 1$ binucleate TGC showed very little or no staining for the VEGFR-2 receptor. The receptor was predominantly expressed in the fetal epithelium from clone $\mathrm{C} 2$ (Figure 5e). Clones $\mathrm{C} 3, \mathrm{C} 5$ and $\mathrm{C} 7$ showed a very similar pattern to non-cloned animals in VEGFR-2 expression (Figure 5g), showing both cytoplasmatic and nuclear staining for the receptor in the fetal and maternal cells. Another distinct pattern of VEGFR-2 expression was observed in the placentome from the clone $\mathrm{C} 4$. In this animal, nuclear staining for VEGFR-2 was strong in fetal cell types and less intense in maternal cells (Figure 5f).

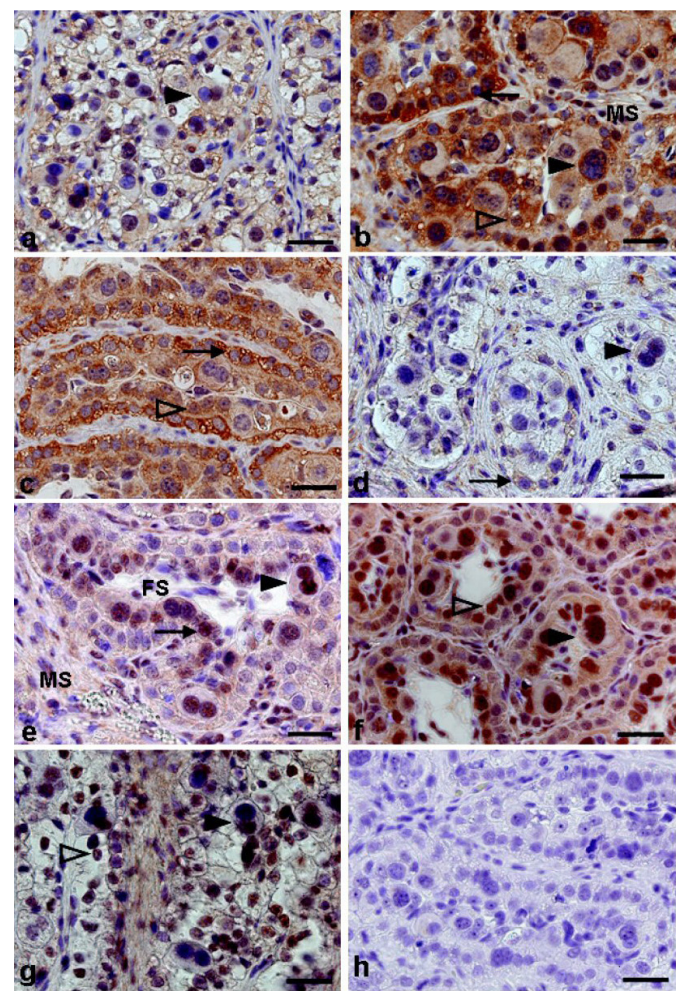

Figure 5. Immunolocalization of VEGFR-1 and VEGFR-2 in placentomes from cloned and non-cloned bovine fetuses. a, b, c, e, and f: Clones C1, C3, C4, C2, and C4, respectively. d and g: Non-cloned animals. h: Negative control. The maternal epithelium (arrow) shows staining for VEGFR-1 in the clones C3 and C4 (b and c). Although less strong when compared with the clones, a similar pattern of expression of VEGFR-1 is observed in the maternal epithelium (arrow) of a non-cloned animal (d). VEGFR-2 staining in fetal epithelium (arrow) in the clone C2 (e). Maternal and fetal placentome cells show signal for the receptor in the clone C4 (f). Arrowheads indicate VEGFR-1 ( $\mathrm{a}, \mathrm{b}$ and $\mathrm{c}$ ) and VEGFR-2 (e, f and g) positively stained binucleate trophoblast giant cells. Open arrowheads indicate VEGFR-1 ( $\mathrm{b}$ and $\mathrm{c}$ ) and VEGFR-2 ( $\mathrm{f}$ and $\mathrm{g}$ ) positively stained fetal mononucleate trophoblast cells. MS = maternal stroma; FS = fetal stroma. Bars: $100 \mu \mathrm{M}$.

With respect to bFGF and its receptor proteins, a less variable pattern of expression was observed among the animals analyzed. All proteins studied were less expressed in placentomes of cloned female bovine fetuses. In addition, cellular distribution of these proteins showed a 
distinct pattern among clones and between cloned and non-cloned bovine placentomes (Figure 6). bFGF protein was localized in maternal and fetal epithelial and stromal cells in placentomes from non-cloned bovine fetuses (Figure 6a). On the other hand, a positive signal for bFGF was only observed in the maternal stromal cells in the placentomes from the cloned fetuses (Figure $6 b)$. The protein was expressed in endothelial cells in cloned and non-cloned animals.

Analyzing the localization of bFGF receptors in the placenta from cloned bovine fetuses, we observed that all three receptors were localized in the maternal and fetal epithelium as well as in stromal and endothelial cells (Figure 6). We observed that all placental cell types, excluding fetal stromal cells expressed the FGFR-1 in the cloned and non-cloned fetuses (Figure 6c and d). FGFR-2 and FGFR-3 were localized in all placental cell types as well (Figure 6e-h); however, FGFR-3 localization was predominantly nuclear in these cells (Figure $6 \mathrm{~g}$ and $\mathrm{h}$ ) in cloned and non-cloned fetuses.

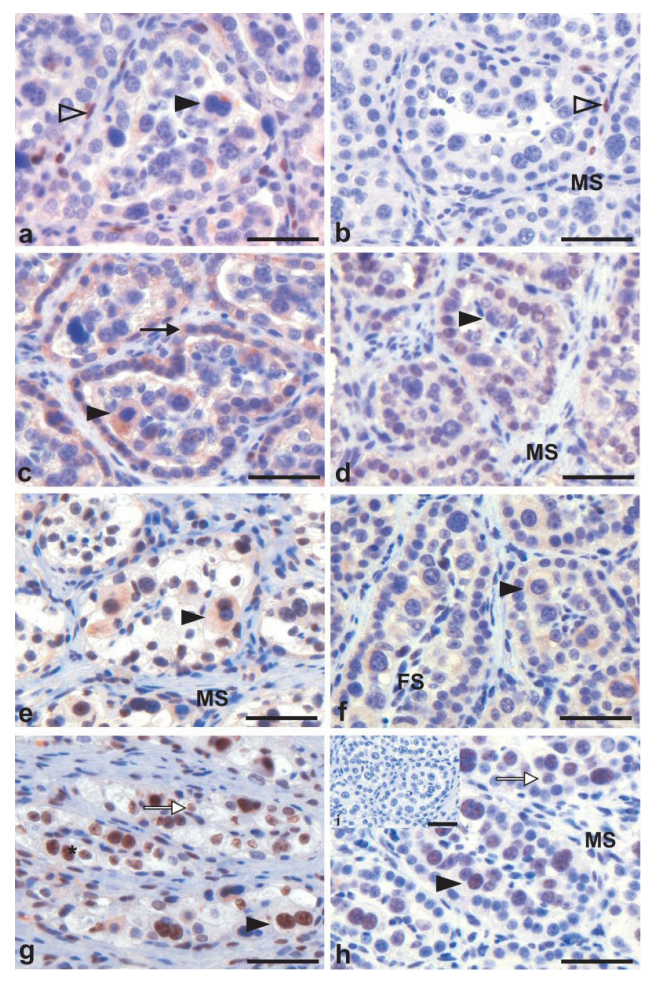

Figure 6. Immunolocalization of bFGF, FGFR-1, FGFR-2, and FGFR-3 in placentomes from cloned and noncloned bovine fetuses. a, c, e, and g: Non-cloned animals. b, d, f, and h: Cloned animals. i: Negative control. All maternal and fetal placental cells showed staining for bFGF in non-cloned fetuses, including the binucleate trophoblast giant cells (TGC) (arrowhead) and maternal stromal cells (open arrowhead) (a). On the other hand, only maternal stromal cells expressed the protein in cloned animals (b). Although less strong when compared with the non-cloned animals, a similar pattern of expression of FGFR-1 was observed in maternal epithelial cells (arrow) and binucleate TGC (arrowhead) in non-cloned (c) and cloned animals (d). FGFR-2 is weakly expressed in binucleate TGC (arrowhead) from clones (f) compared with non-cloned animals (e). FGFR-3 staining was predominantly nuclear in binucleate TGC (arrowhead) and maternal epithelial cells (open arrow) from non-cloned (g) and cloned fetuses (h). MS = maternal stroma; FS = fetal stroma. Bars: $100 \mu \mathrm{M}$. 


\section{DISCUSSION}

Extensive placental angiogenesis is essential for a successful maintenance of gestation (Reynolds and Redmer, 1995, 2001). VEGF-A and bFGF have been demonstrated to be the two major angiogenic factors inducing placental vessel development (Reynolds and Redmer, 1995, 2001). Several reports have described morphological analysis of the placenta from cloned bovines and there is a consensus that numerous alterations are a common feature in these placentae, including placental overgrowth and vascular disorders (Hill et al., 2000; Heyman et al., 2002; Constant et al., 2006; Miglino et al., 2007).

Altered vascular development of placenta from clones could be due to modifications in the expression of placental factors (Constant et al., 2006). Placental gene expression is influenced by cytosine methylation pattern of the DNA, and improper reprogramming of DNA methylation in the chorion of clones leads to radically altered gene expression profiles in the placenta (Dindot et al., 2004). Based on that, we proposed to investigate VEGF-A and bFGF system expression in placentas from cloned bovines. Placentomes here studied were previously submitted to morphological analysis (Miglino et al., 2007), and all samples displayed alterations, including deranged vascular structure in the cotyledons. Herein, we clearly demonstrate that both systems have altered expression in the placentomes at term, which could be related to abnormalities in the placental development as well as fetal viability. In fact, although nuclear transfer-derived placentae supported gestation until term, we observed low survival rates of the offspring (36.75\%). Survival of fetuses was not related to degree of perturbation in gene and protein expression, suggesting that individual compensatory mechanisms could be triggered during gestation in order to overcome disrupted expression of important genes in the placenta (Constant et al., 2006) allowing gestation to come to term, however, down- or up-regulation of important vasculogenic growth factors and respective receptors might have an impact on placental function and, consequently, on fetal development and survival. Previous investigation demonstrated that expression of most angiogenic factors, including VEGF and VEGFR-1, is not altered as a result of nuclear transfer procedure in placental tissues at day 30 of gestation (Hoffert-Goeres et al., 2007). These data, associated with our results, suggest that perturbations in vascular development may occur throughout gestation.

In this study, we identified a decrease in bFGF and a tendency for higher VEGF-A expression in female but not in male nuclear transfer-derived term placentomes. In fact, the modulatory role of bFGF in the VEGF and VEGFR expression has already been described in the corpus luteum (Stavri et al., 1995; Gabler et al., 2004; Yamashita et al., 2008) and determines the ideal balance of angiogenic factors and corpus luteum vascularization progress. As observed in the corpus luteum, this mechanism may be active also in the placenta and the decrease of bFGF and FGFR expression may determine an increase of VEGF-A mRNA expression in the placentomes. Interestingly, disruption of bFGF system occurred only in female placentomes, which could be related to deficient X-chromosome inactivation, which in turn depends also on methylation of cytosine residues (Cezar et al., 2003). Different methylation patterns of chorion-specific genes have been described in male and female nuclear transferderived bovine embryos (Dindot et al., 2004), contributing to the understanding that some genes may be altered in the placenta of one gender and not the other. In addition, it is possible that bFGF functions not related to angiogenesis may be altered in the placenta of cloned fetuses, contributing to the decreased survival rate of females (25\%) compared to males $(50 \%)$. Male-cloned fetuses seem to compensate vascular maintenance demands, at least in terms of 
VEGFR-2 up-regulation, which could also influence bFGF system expression (Gabler et al., 2004) and regulate its transcription to normal levels.

During early gestation, a physiological condition of hypoxia is observed in the uterine environment (James et al., 2006) and hypoxia-induced factors, such as VEGF-A, bFGF and their receptors, have particular importance in the vasculogenesis and angiogenesis required to establish an adequate vascular network and support both placental and fetal development (Wheeler et al., 1995). Herein we demonstrated that VEGF-A and bFGF systems are expressed at late gestation in placental vessels, reinforcing their importance in the maintenance of vasculature and control of vascular permeability throughout pregnancy (Cheung, 1997). Furthermore, the localization of VEGF and bFGF receptors in maternal and fetal epithelial and stromal cells suggests that both growth factors might have other biological actions in the bovine placental tissue. In fact, the spatialtemporal distribution of VEGF-A and bFGF systems during gestation indicates that these growth factors play different roles in the placenta (Winther et al., 1999; Pfarrer et al., 2006a,b). We identified differences in cellular distribution of target proteins comparing cloned and non-cloned placental tissues as well as among clones. These data indicate that function of VEGF and bFGF as a local paracrine/autocrine factor (Pfarrer et al., 2006a,b) could be compromised, due to the absence of these growth factors or their receptors in specific placental cell types. This lack may lead to altered placental function and contribute to decreased survival of cloned bovine fetuses.

Besides individual differences in protein cellular localization, we observed individual variations in the levels of gene expression in the placenta of our cloned animals, especially considering VEGF-A system. The same observation has been described in the literature. A study with Sertoli cell- and cumulus cell-derived clones demonstrated that clones differed from each other and from normal individuals produced by sexual reproduction and only a few genes were universally affected in all clones (Kohda et al., 2005). Variations in the expression of crucial genes related to placental development were observed among bovine blastocysts submitted to the same nuclear transfer process (Hall et al., 2005). In term placentae from mice, important alterations of imprinted genes were observed among clones derived from stem cell nuclear transfer (Humpherys et al., 2002). Moreover, another study with term murine placenta demonstrated different mean expression rates among cloned and non-cloned animals for several imprinted and non-imprinted genes, including VEGFR-2 (Inoue et al., 2002). All clones from this study were derived from adult fibroblast nuclear transfer and differences were observed between means of VEGFR-2 and bFGF system gene expression in the placental tissue from cloned and non-cloned bovine fetuses. In addition, individual variations were more evident among clones. Combined, these data indicate the importance of individual analyses of cloned animals, since the variation in mean expression levels could mask gene expression abnormalities present in individual clones.

In summary, we reported that the VEGF-A and bFGF systems have altered expression in nuclear transfer-derived placentae at term gestation. The fact that cloned gestations came to term even though the expression of important angiogenic factors was disturbed in the placenta, emphasizes the concept that the most remarkable changes in the expression of angiogenic factors from compromised pregnancies must be found during the course of gestation (Cezar et al., 2003; Dindot et al., 2004). We show modified late-gestation expression of VEGF-A and bFGF for the first time. These alterations and possibly modifications in other genes, as suggested by Everts and collaborators (2008), can effectively contribute to the described phenotypic (Miglino et al., 2007) disturbances found in these animals and consequently to the poor fetal development and low survival rates of the clones. 


\section{ACKNOWLEDGMENTS}

The authors would like to thank FAPESP (grant \#02/07392-7), CAPES (PROBRAL grant \#272/07) and DAAD (PROBRAL grant \#D/06/33937) for their financial support.

\section{REFERENCES}

Campbell KH, Alberio R, Choi I, Fisher P, et al. (2005). Cloning: eight years after Dolly. Reprod. Domest. Anim. 40: 256-268.

Carmeliet P and Storkebaum E (2002). Vascular and neuronal effects of VEGF in the nervous system: implications for neurological disorders. Semin. Cell Dev. Biol. 13: 39-53.

Cebe-Suarez S, Zehnder-Fjallman A and Ballmer-Hofer K (2006). The role of VEGF receptors in angiogenesis; complex partnerships. Cell Mol. Life Sci. 63: 601-615.

Cezar GG, Bartolomei MS, Forsberg EJ, First NL, et al. (2003). Genome-wide epigenetic alterations in cloned bovine fetuses. Biol. Reprod. 68: 1009-1014.

Cheung CY (1997). Vascular endothelial growth factor: possible role in fetal development and placental function. J. Soc. Gynecol. Investig. 4: 169-177.

Clauss M, Weich H, Breier G, Knies U, et al. (1996). The vascular endothelial growth factor receptor Flt-1 mediates biological activities. Implications for a functional role of placenta growth factor in monocyte activation and chemotaxis. J. Biol. Chem. 271: 17629-17634.

Constant F, Guillomot M, Heyman Y, Vignon X, et al. (2006). Large offspring or large placenta syndrome? Morphometric analysis of late gestation bovine placentomes from somatic nuclear transfer pregnancies complicated by hydrallantois. Biol. Reprod. 75: 122-130.

De Sousa PA, King T, Harkness L, Young LE, et al. (2001). Evaluation of gestational deficiencies in cloned sheep fetuses and placentae. Biol. Reprod. 65: 23-30.

Dindot SV, Farin PW, Farin CE, Romano J, et al. (2004). Epigenetic and genomic imprinting analysis in nuclear transfer derived Bos gaurus/Bos taurus hybrid fetuses. Biol. Reprod. 71: 470-478.

Everts RE, Chavatte-Palmer P, Razzak A, Hue I, et al. (2008). Aberrant gene expression patterns in placentomes are associated with phenotypically normal and abnormal cattle cloned by somatic cell nuclear transfer. Physiol. Genomics 33: 65-77.

Fulka J Jr and Fulka H (2007). Somatic cell nuclear transfer (SCNT) in mammals: the cytoplast and its reprogramming activities. Adv. Exp. Med. Biol. 591: 93-102.

Gabler C, Plath-Gabler A, Killian GJ, Berisha B, et al. (2004). Expression pattern of fibroblast growth factor (FGF) and vascular endothelial growth factor (VEGF) system members in bovine corpus luteum endothelial cells during treatment with FGF-2, VEGF or oestradiol. Reprod. Domest. Anim. 39: 321-327.

Gospodarowicz D (1991). Biological activities of fibroblast growth factors. Ann. N. Y. Acad. Sci. 638: 1-8.

Guerra DM, Giometti IC, Price CA, Andrade PB, et al. (2008). Expression of fibroblast growth factor receptors during development and regression of the bovine corpus luteum. Reprod. Fertil. Dev. 20: 659-664.

Hall VJ, Ruddock NT and French AJ (2005). Expression profiling of genes crucial for placental and preimplantation development in bovine in vivo, in vitro, and nuclear transfer blastocysts. Mol. Reprod. Dev. 72: 16-24.

Heyman Y, Chavatte-Palmer P, LeBourhis D, Camous S, et al. (2002). Frequency and occurrence of late-gestation losses from cattle cloned embryos. Biol. Reprod. 66: 6-13.

Hill JR, Burghardt RC, Jones K, Long CR, et al. (2000). Evidence for placental abnormality as the major cause of mortality in first-trimester somatic cell cloned bovine fetuses. Biol. Reprod. 63: 1787-1794.

Hoffert-Goeres KA, Batchelder CA, Bertolini M, Moyer AL, et al. (2007). Angiogenesis in day-30 bovine pregnancies derived from nuclear transfer. Cloning Stem Cells 9: 595-607.

Humpherys D, Eggan K, Akutsu H, Friedman A, et al. (2002). Abnormal gene expression in cloned mice derived from embryonic stem cell and cumulus cell nuclei. Proc. Natl. Acad. Sci. U. S. A. 99: 12889-12894.

Inoue K, Kohda T, Lee J, Ogonuki N, et al. (2002). Faithful expression of imprinted genes in cloned mice. Science 295: 297.

James JL, Stone PR and Chamley LW (2006). The regulation of trophoblast differentiation by oxygen in the first trimester of pregnancy. Hum. Reprod. Update 12: 137-144.

Klint P and Claesson-Welsh L (1999). Signal transduction by fibroblast growth factor receptors. Front Biosci. 4: D165-D177.

Kohda T, Inoue K, Ogonuki N, Miki H, et al. (2005). Variation in gene expression and aberrantly regulated chromosome regions in cloned mice. Biol. Reprod. 73: 1302-1311. 
Loi P, Clinton M, Vackova I, Fulka J Jr, et al. (2006). Placental abnormalities associated with post-natal mortality in sheep somatic cell clones. Theriogenology 65: 1110-1121.

Malassine A, Frendo JL and Evain-Brion D (2003). A comparison of placental development and endocrine functions between the human and mouse model. Hum. Reprod. Update 9: 531-539.

Miglino MA, Pereira FT, Visintin JA, Garcia JM, et al. (2007). Placentation in cloned cattle: structure and microvascular architecture. Theriogenology 68: 604-617.

Ohgane J, Wakayama T, Kogo Y, Senda S, et al. (2001). DNA methylation variation in cloned mice. Genesis 30: 45-50.

Otrock ZK, Makarem JA and Shamseddine AI (2007). Vascular endothelial growth factor family of ligands and receptors: review. Blood Cells Mol. Dis. 38: 258-268.

Pfarrer C, Weise S, Berisha B, Schams D, et al. (2006a). Fibroblast growth factor (FGF)-1, FGF2, FGF7 and FGF receptors are uniformly expressed in trophoblast giant cells during restricted trophoblast invasion in cows. Placenta 27: 758770.

Pfarrer CD, Ruziwa SD, Winther H, Callesen H, et al. (2006b). Localization of vascular endothelial growth factor (VEGF) and its receptors VEGFR-1 and VEGFR-2 in bovine placentomes from implantation until term. Placenta 27: 889898.

Reynolds LP and Redmer DA (1995). Utero-placental vascular development and placental function. J. Anim. Sci. 73: 1839-1851.

Reynolds LP and Redmer DA (2001). Angiogenesis in the placenta. Biol. Reprod. 64: 1033-1040.

Roussel Y, Harris A, Lee MH and Wilks M (2007). Novel methods of quantitative real-time PCR data analysis in a murine Helicobacter pylori vaccine model. Vaccine 25: 2919-2929.

Schlessinger J, Lax I and Lemmon M (1995). Regulation of growth factor activation by proteoglycans: what is the role of the low affinity receptors? Cell 83: 357-360.

Stavri GT, Zachary IC, Baskerville PA, Martin JF, et al. (1995). Basic fibroblast growth factor upregulates the expression of vascular endothelial growth factor in vascular smooth muscle cells. Synergistic interaction with hypoxia. Circulation 92: 11-14.

Wheeler T, Elcock CL and Anthony FW (1995). Angiogenesis and the placental environment. Placenta 16: 289-296.

Winther H, Ahmed A and Dantzer V (1999). Immunohistochemical localization of vascular endothelial growth factor (VEGF) and its two specific receptors, Flt-1 and KDR, in the porcine placenta and non-pregnant uterus. Placenta 20: 35-43.

Yamashita H, Kamada D, Shirasuna K, Matsui M, et al. (2008). Effect of local neutralization of basic fibroblast growth factor or vascular endothelial growth factor by a specific antibody on the development of the corpus luteum in the cow. Mol. Reprod. Dev. 75: 1449-1456.

Yamazaki W, Ferreira CR, Meo SC, Leal CL, et al. (2005). Use of strontium in the activation of bovine oocytes reconstructed by somatic cell nuclear transfer. Zygote 13: 295-302. 